\title{
Formação continuada para o uso das Tecnologias de Informação e Comunicação
}

\author{
Continued Training for the use of Information and Communication \\ Technologies \\ Shirley Takeco Gobara \\ Professora-Pesquisadora do Programa de Pós-Graduação em Educação e do \\ Programa de Pós-Graduação em Ensino de Ciências da UFMS. \\ shirley.gobara@ufms.br
}

\begin{abstract}
Resumo
O artigo apresenta os resultados de uma experiência de formação continuada para o uso das Tecnologias de Informação e Comunicação (TICs). Trata-se de uma pesquisa realizada com professores dos anos finais do Ensino Fundamental de uma escola da Rede Estadual de São Paulo, que busca evidenciar o sentido epistemológico de a prática pedagógica estar fundamentada em uma teoria educacional que possibilite o processo de reflexão e a construção do conhecimento. Verificou-se que a Teoria das Situações é um modelo teórico que possibilita a formação do professor reflexivo e autônomo e aponta para a importância do trabalho pedagógico coletivo na escola, na perspectiva da formação permanente, continuada e em serviço e, principalmente, da reflexão sobre a prática.
\end{abstract}

Palavras-chave: Formação Continuada de Professores. Professor Autônomo. Tecnologias da Informação e da Comunicação. Teoria das Situações Didáticas.

\begin{abstract}
This article presents the results of an experiment for the use of Information and Communication Technologies (ICT) in continued education. We presented a research made with teachers from final years of High School Teaching of a Public School in the State of São Paulo. This research shows that the epistemological sense of the pedagogical practice is related with an educational theory that enables the reflection process and knowledge construction. It was found that the Theory of Situations is a theoretical model that enables the formation of autonomous and reflective teacher and point out the emphasis of collective pedagogical work in school, in the perspective of lifelong learning, continued and in work service, especially the reflection of the practice.
\end{abstract}

Key words: Autonomous Teacher. Continuing Education of Teachers. Information and Communication Technology. Theory of Didactical Situations. 


\section{Introdução}

A sociedade tem passado por grandes transformações decorrentes dos avanços tecnológicos, em particular aquelas oriundas das Tecnologias da Informação e da Comunicação (TICs). A facilidade de acesso à informação e as múltiplas possibilidades de comunicação e interação, principalmente aquelas proporcionadas pela Internet, estão transformando radicalmente e de forma decisiva o mundo em que vivemos.

A evolução tecnológica não se restringe apenas aos novos usos de determinados equipamentos e produtos. Ela altera comportamentos. A ampliação e a banalização do uso de determinada tecnologia impõem-se à cultura existente e transformam não apenas o comportamento individual, mas o de todo o grupo social. (KENSKI, 2007, p. 21)

A rapidez com que a informação chega às nossas casas, proporcionada pelos veículos de comunicação, escritos ou falados, particularmente pelas redes virtuais de informação, tem trazido para a sociedade mudanças significativas caracterizando-a como a Sociedade da Informação. A evolução ocorrida da informação impressa (livro, revistas, jornais etc.) para a informação midiática, por meio da televisão e do vídeo, e destes para o computador e a internet, foi tão rápida que necessitamos permanentemente explorar as várias possibilidades de uso destes últimos. Consequentemente, a educação também está passando por novos desafios: como educar os indivíduos para a Sociedade da Informação?

O programa de informatização das escolas públicas é uma realidade. A maioria das escolas possui pelo menos um laboratório de informática devido à iniciativa do Ministério da Educação (MEC) com o Programa Nacional de Tecnologia Educacional - Proinfo (BRASIL, 2000) em disponibilizar ao ensino público programas de incentivo tecnológico e financeiro que possibilitaram a implantação desses laboratórios, com a perspectiva de inserir professores e alunos no universo das tecnologias da informação e da comunicação.

Uma mudança qualitativa no processo de ensino e aprendizagem deverá acontecer como consequência da disseminação e uso dessas tecnologias informacionais. De acordo com Moran (2000), educar na Sociedade da Informação 
é estar em processo permanente de aprendizagem, é ser educador e educando. Embora o acesso a qualquer tipo de informação seja disponibilizado irrestritamente, o problema maior está relacionado com a veracidade dessas informações, a democratização dos meios para acessá-las (inclusão digital e social) e a forma como os alunos utilizam e se apropriam dessas informações. Consequentemente, outro questionamento importante se coloca: qual o papel da escola e do professor nesse contexto?

Para que as tecnologias façam parte do cotidiano escolar é necessário que os educadores se apropriem dos conhecimentos técnicos (apropriação tecnológica) e dos conhecimentos sobre o potencial educativo relacionado ao uso dessas tecnologias, isto é, integrar esses recursos informacionais em suas práticas pedagógicas cotidianas. Isso implica uma mudança do papel tradicional do professor, visto que exige mudanças na sua forma de atuação para que passe a exercer um papel de orientador e organizador de ambientes virtuais de aprendizagem.

Preocupados com a inserção das tecnologias informacionais no ambiente escolar e com as dificuldades dos professores em utilizá-las para propiciar a construção do conhecimento pelos alunos, desde meados da década de 90 do século XX estamos desenvolvendo pesquisas cujo objeto de investigação é o uso das tecnologias na educação. Essas investigações tratam de duas temáticas de interesse: o uso das tecnologias para promover a aprendizagem do aluno; as dificuldades dos professores para usar as tecnologias associadas ao processo de aprendizagem mediado pelo computador, verificadas tanto em sua formação inicial quanto na continuada.

No entanto, usar esses recursos no contexto escolar não significa melhoria na prática do professor e nas atividades pedagógicas. É necessário que essas tecnologias sejam integradas ao currículo escolar, oferendo suporte para experiências educativas inovadoras e significativas. (ALMEIDA; VALENTE, 2011)

O presente artigo traz uma reflexão sobre o papel do professor na inserção dessas tecnologias no ambiente escolar e discute, fundamentalmente, uma proposta de formação continuada para professores apoiada na Teoria das Situações Didáticas desenvolvida por Guy Brousseau (1986; 1983). Essa proposta será explicitada a partir dos resultados de uma das experiências de formação em serviço desenvolvida especificamente para investigar as dificuldades apresentadas por professores do Ensino Fundamental ( $5^{\mathrm{a}}$ a $8^{\mathrm{a}}$ séries) no uso da informática como instrumento motivador de promoção da aprendizagem. (PARANHOS e GOBARA, 2005; 2009) 
Os professores, que participaram voluntariamente dessa pesquisa, tiveram a oportunidade de vivenciar um processo participativo envolvendo planejamento, discussão, reflexão e execução em torno de um projeto pedagógico interdisciplinar, com foco na utilização dos recursos da informática presentes na escola e com objetivo de investigar as suas dificuldades no uso das tecnologias.

O desenvolvimento da pesquisa foi alicerçado em alguns pressupostos teórico-metodológicos da pesquisa-ação (THIOLLENT, 1998), dada a escolha do contexto da pesquisa: um grupo de estudo em formação. A formação também foi usada como meio de investigação e "meio didático", de acordo com a Teoria das Situações Didáticas. (BROUSSEAU, 1986, 1983)

\section{A Teoria das Situações}

A didática francesa estuda os fenômenos de ensino e da aprendizagem tomando como objeto de estudo o sistema didático representado pelo diagrama da Figura 1:

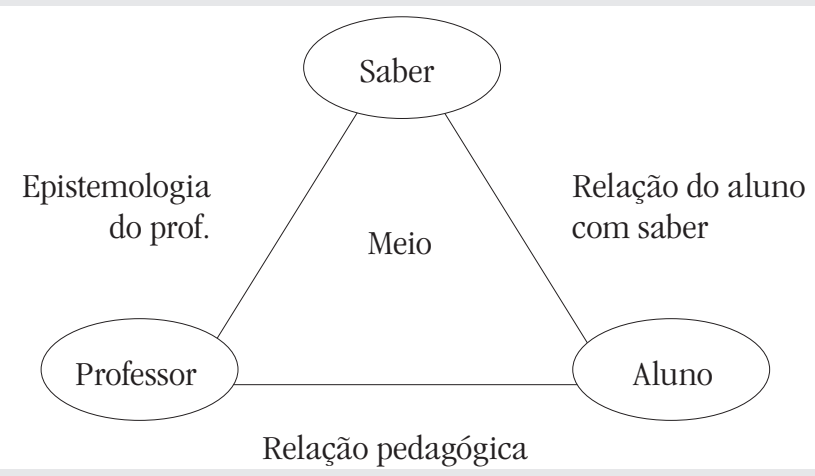

Figura 1: Sistema Didático (HENRY, 1992)

Diferentes aspectos influenciam uma situação de aprendizado dentro de um sistema didático: a natureza do saber, os alunos e os seus processos cognitivos e as intervenções pedagógicas (mediadas pelo professor) que dão status de saber científico ao conhecimento em construção pelo aluno. Entretanto, para que o sistema didático se complete, é necessário introduzir outro elemento: o "meio didático", no 
qual alunos e professores estabelecem relações de ensino e aprendizagem. Como meio, podem-se considerar todos os elementos que estão disponíveis ao aluno para que ele possa resolver o problema proposto pelo professor.

De acordo com Brousseau (1986), para que haja aprendizagem o professor deve efetuar não a comunicação de um conhecimento, mas propor uma situação em que esse conhecimento seja necessário à obtenção da solução e que permita a "devolução" de um bom problema ao aluno. O aluno, um dos elementos do sistema didático, aprende por adaptação ao "meio", isto é, ele deve adequar o seu conhecimento à situação problemática na qual se encontra. O "meio" deve opor-se à ação do aluno; se ele conseguir resolver o problema, como consequência, apropria-se do saber em questão, ao mesmo tempo em que mostra ao professor a prova dessa apropriação.

A escolha por essa teoria reside no fato de que o uso das TICs constitui um meio muito favorável e propício para novas estratégias, nas quais o aluno aporta seus conhecimentos prévios numa situação de conflitos e desequilíbrios. E a "retroação" do meio é capaz de levá-lo à superação desses conflitos e de contribuir para a aprendizagem de novos conhecimentos.

Em conformidade com a Teoria das Situações, um dos objetivos do processo de aprendizagem é propiciar ao aluno o desenvolvimento de certa autonomia intelectual que o capacite a utilizar, por si mesmo, o saber escolar em situação não prevista no contexto de ensino, ou quando a aprendizagem ocorre na ausência de qualquer indicação, pelo professor, da intenção de ensinar. Trata-se, neste caso, de uma situação denominada a-didática:

Quando o aluno se torna capaz de pôr em funcionamento e utilizar por si mesmo o saber que está construindo, em situação não prevista em qualquer contexto de ensino e também na ausência de qualquer indicação intencional. (BROUSSEAU, 1986, p. 49)

No processo de aprendizagem, o aluno deve encontrar-se em uma situação de pesquisa para a solução de um problema; nessa circunstância, diversos procedimentos de raciocínio ocorrem sem o controle do professor, ou seja, neste processo "[...] deve haver condições para que o aluno realize ele mesmo suas aproximações, mobilize seus conhecimentos e seja capaz de explicitar seus procedimentos e raciocínios utilizados [...]”. (FREITAS, 2002, p. 72) 
Nesse contexto, questiona-se o papel do professor, visto que ele é parte obrigatória do sistema didático. Contudo, nesta situação, ele deixa de exercer a função de transmissor do conhecimento e assume a estruturação didática das situações de ensino. $O$ trabalho pedagógico inicia-se exatamente com a escolha de um bom problema, que deve ser compatível com o nível intelectual do aluno. Para isso, é necessário que o professor tenha clareza dos procedimentos que espera dos alunos, baseado no conhecimento que tem deles e da realidade de sala de aula.

A fim de descrever as ações dos alunos ao longo da resolução de um problema, Brousseau (1983) propôs a seguinte tipologia de situações a-didáticas:

- "situações de ação": a solução de um problema ocorre por meio de ações diretas e o conhecimento produzido pelo aluno tem uma função prática e operacional. Predomina o aspecto experimental do conhecimento. $\mathrm{O}$ aluno resolve um problema de forma intuitiva sem explicitar modelos ou teorias que o levaram ao resultado.

- "situações de formulação": o aluno utiliza modelos ou esquemas teóricos explícitos e mais elaborados na resolução do problema. Existe a intenção implícita de verificar se o modelo construído resolve corretamente o problema.

- "situações de validação": o aluno usa mecanismos de prova em busca da comprovação ou da rejeição do modelo ou teoria construído por ele no processo de aprendizagem.

Essa divisão de situações faz parte dos procedimentos discentes identificados pelo professor (ou pesquisador) e serve apenas para facilitar a compreensão do processo de construção do conhecimento, sendo que elas entrelaçam-se fortemente umas às outras. Brousseau (1986) esclarece que essas três categorias têm a finalidade de analisar os aspectos fundamentais do processo de aprendizagem.

\section{A Teoria das Situações e a formação continuada de professores no uso das TIC}

Para materializar a proposta de formação continuada e em serviço com base nos pressupostos da Teoria da Situação (1986; 1983), apresentamos uma síntese 
analítica da pesquisa realizada ${ }^{1}$ com o grupo de estudos constituído pelas pesquisadoras e pelos professores de $5^{\mathrm{a}}$ a $8^{\mathrm{a}}$ séries do Ensino Fundamental de uma escola de Mirandópolis, da Rede Pública de Ensino do Estado de São Paulo.

A primeira ação desenvolvida para o estabelecimento desse grupo foi o levantamento do perfil dos profissionais que estavam atuando na escola escolhida como campo de pesquisa. Todos os professores (24) foram convidados a participar do grupo de estudos na condição de professor-pesquisador; destes, doze aceitaram e somente nove permaneceram (3 de Matemática, 3 de Língua Portuguesa, 2 de História, 1 de Geografia e a coordenadora pedagógica do Ensino Fundamental).

Para o desenvolvimento da pesquisa era fundamental que o professor assumisse a responsabilidade de participar do grupo e as consequências resultantes dessa participação, por exemplo, nos encontros semanais, no projeto de trabalho a desenvolver com os alunos e, principalmente, na reflexão sobre a sua prática. De acordo com a Teoria das Situações, o grupo, no decorrer do trabalho, deveria assumir o problema e buscar formas para utilizar o computador e os recursos disponíveis na escola e/ou na World Wide Web (WEB) (em português, teia mundial). O trabalho foi desenvolvido durante sete meses, totalizando 14 seminários que ocorreram no Horário de Trabalho Pedagógico Coletivo (HTPC) e que foram planejados para criar um contexto favorável que desenvolvesse a capacidade reflexiva. (ALARCÃO, 2003)

Desde o momento em que o grupo passou a definir as atividades a serem desenvolvidas nos seminários até a execução do projeto, considera-se que o grupo iniciou o seu processo de autonomia. Os seminários foram realizados em cinco etapas planejadas pelo grupo: a primeira compreendia o levantamento do problema e a análise de referencial teórico para sua abordagem; a segunda, a análise dos softwares disponíveis, por disciplina, na escola; a terceira, o planejamento de um projeto interdisciplinar utilizando a informática educativa; a quarta, a aplicação desse projeto para uma turma de $8^{a}$ série do Ensino Fundamental. Após a aplicação do projeto, foi feita uma avaliação do trabalho realizado, objetivando o levantamento final das dificuldades encontradas e dos progressos alcançados ao longo da experiência.

Como parte do "meio didático" e para que o grupo delimitasse o problema a ser resolvido, mostramos, inicialmente, um vídeo ${ }^{2}$ que apresentava o projeto de implantação dos laboratórios na Rede de Ensino do Estado de São Paulo. Considerando que os professores participantes não conheciam o conteúdo desse 
vídeo, ele serviu para que o grupo fizesse uma análise da real situação em que se encontravam, que era muito diferente daquela apresentada no vídeo.

Um aspecto fundamental na Teoria das Situações é a importância de o grupo aceitar e assumir o desafio de resolver o problema como sendo do grupo, dado que, inicialmente, foi proposto pelos pesquisadores. O grupo questionou o fato de que a realidade apresentada no vídeo não condizia com a da escola e com a vivência do grupo, como podemos verificar no depoimento da coordenadora:

O que apresentaram sobre internet não é a realidade, pois a escola só possui uma linha telefônica para atender toda a escola, secretaria, direção etc. Quanto aos equipamentos, a escola recebeu o scanner e a impressora, além dos dez computadores, mas não tem dinheiro para comprar tinta. O que é real no vídeo é o acervo de softwares que receberam.

Uma professora participante do grupo completou: "O vídeo só apresentou os sucessos e não as dificuldades que encontramos. Na teoria é bonito, mas quantos alunos tinham nas turmas mostradas?" O grupo também levantou a questão apresentada no vídeo quanto à capacitação de professores, argumentando que eles tinham dificuldades em participar de tais processos.

Brandão (2002) destaca que o estudo da especificidade de um discurso se faz colocando-o em relação aos outros discursos. Dessa forma, verificamos uma lacuna entre o discurso oficial e o discurso dos professores, pois enquanto no primeiro é apresentado um quadro de utilização da informática como recurso pedagógico eficiente e com excelentes resultados, no segundo, dos sujeitos investigados, encontramos uma abordagem que aponta dificuldades a serem vencidas. Essa lacuna entre os dois discursos possibilitou-nos a "devolução" do problema em questão para o grupo, levando-o a refletir sobre as contradições apresentadas e estimulando seus elementos a participar do grupo como pesquisadores em busca de possibilidades de superação das dificuldades.

Além do vídeo, o grupo participou de uma atividade prática utilizando um dos softwares disponíveis na escola. As duas atividades proporcionaram a reflexão sobre as possibilidades do uso da informática na educação, além de oferecer aos participantes oportunidades para exporem os seus conhecimentos, 
as dificuldades e até mesmo suas angústias, de forma que pudessem familiarizar-se com os softwares disponíveis. Consideramos essas atividades como situação de contextualização do saber (BROUSSEAU, 1986), pois apresentamos uma atividade prática com o objetivo de provocar os professores a iniciarem um processo de investigação, passando, inclusive, pela reflexão sobre a ação realizada (DEWEY, 1988). Em todos os seminários, o grupo foi incentivado a realizar uma atividade prática.

A segunda fase do trabalho do grupo constituiu-se na análise dos softwares disponíveis na escola, quando os participantes perceberam seu desconhecimento sobre a maioria deles. Consideramos que nessa fase os professores apresentaram atitudes que demonstram um nível de autonomia (FREIRE, 1996) fundamental para que o grupo assumisse o problema que havia sido proposto, no seminário anterior, como um desafio de pesquisa, pois a decisão de exploração dos softwares e o planejamento das estratégias para analisá-los foram definidos pelo coletivo. o grupo adotou essa análise como uma possibilidade na busca de solução do problema em questão, situação tipicamente identificada como de "ação", de acordo com a Teoria das Situações. Os softwares foram classificados e explorados por disciplina e os critérios de análise foram livremente propostos pelo grupo, porém, no decorrer dos três seminários, alguns parâmetros foram definidos e usados pelo coletivo: facilidade de utilização do software, cópia de livros impressos, interatividade, criatividade e conteúdo.

Na reflexão sobre a ação realizada nesses seminários, na qual os softwares foram analisados, detectamos falas que evidenciam a importância desse momento:

[...] foi muito válido. Eu estava com um cd então eu encontrava alguma coisa que era do interesse delas, era troca de experiências. Elas encontravam alguma coisa, aí nós íamos todas lá no computador delas. Às vezes você pensa que tem um grande material na mão e, às vezes, não é aquilo que encontramos (depoimento verbal da professora de Língua Portuguesa).

Nos discursos coletados, notamos que, embora a escola tenha recebido bons softwares e que um programa de capacitação tenha sido oferecido ao corpo docente, a maioria dos professores nunca tinha ido à sala-ambiente de informática, nem mesmo para conhecer o material disponível. Os discursos evidenciam 
a dissociação dos cursos de capacitação com a realidade local e as reais necessidades dos professores. As ações dos docentes durante a análise dos softwares são evidências do desencadeamento de um processo de autonomia grupal, na medida em que os participantes assumiram a responsabilidade pela definição dos aspectos relevantes e pela utilização dos softwares, mesmo que eles apresentassem algumas limitações técnicas.

Uma "situação de formulação", conforme definido na Teoria das Situações, pode ser compreendida como o momento em que o aluno avança na formulação de soluções para o problema, mesmo que o faça de forma interiorizada. 0 trabalho em grupo foi fundamental neste momento, pois a formulação de soluções para a análise do software foi realizada coletivamente, o que podemos constatar, por exemplo, no seguinte discurso:

Nós tivemos um momento de estar aqui só para ver aquilo. Sabe, tipo pegar o software, entrar em duas, em três da minha área (falando do grupo de matemática). Que nem eu e a professora E (matemática) e a professora G (matemática), nós sentávamos e ali íamos explorando, resolvia exercícios do software, tinha algum software que eu conhecia e a professora E não conhecia. Então ela dizia: Ah, como é que é? Então mostrei para ela. Então a gente fez esta troca, eu achei que isso foi assim muito válido, foi muito válido (depoimento verbal da professora de Matemática).

Por fim, o grupo apresentou a necessidade de estudar estratégias de utilização dos softwares baseadas em um referencial teórico. Tal necessidade foi interpretada como a "situação de validação" definida pela Teoria de Situações, a qual afirma que o aluno precisa "[...] elaborar algum tipo de prova daquilo que já se afirmou de outra forma pela ação [...]" (FREITAS, 2002, p. 80), ou seja, a escolha do software deve ser justificada pela teoria sobre a sua utilização. Portanto, consideramos que essa fase desenvolveu-se como uma situação a-didática - uma situação em que a intenção de ensinar está implícita, mascarada - em que, no caso desta pesquisa, os professores passaram pelas fases da ação, formulação e validação, o que foi fundamental para o desenvolvimento de toda a pesquisa e para seu resultado. 
A terceira etapa do trabalho foi reservada para o planejamento do projeto a ser aplicado com os alunos. O grupo decidiu desenvolver um projeto interdisciplinar sobre o tema "A volta ao mundo nas Olimpíadas", que envolveu as disciplinas de Língua Portuguesa, Matemática, História e Geografia, para aplicação numa turma de $8^{a}$ série do Ensino Fundamental, ao longo de 15 aulas, com três delas utilizadas para as apresentações dos trabalhos dos alunos.

A aplicação do projeto demonstrou claramente a autonomia que o grupo foi adquirindo gradativamente, visto que assumiu a proposta do trabalho, planejou e aplicou o projeto.

Os professores também realizaram estudos sobre a Teoria das Situações e a importância da contextualização e da devolução de bons problemas, e demonstraram a apropriação desses conhecimentos ao construir desafios para os alunos que desenvolvessem o raciocínio, a interação e a construção do conhecimento.

Avaliando o primeiro dia do projeto, a professora de Geografia declarou:

Eu acho que tudo, no primeiro momento, a gente sente insegurança, um medo de não dar certo, como será que vai ser, aquela expectativa. [...] mas a gente dentro da nossa expectativa, eu acredito, que a gente vai estar alcançando o nosso objetivo, sim [...]

Outra, acrescentou:

Olha, eu também, no primeiro momento, achei que eles poderiam ter mais dificuldades. Mas, depois, eu percebi que estavam também buscando saídas e como, geralmente, o aluno tem o hábito de chamar muito, eles chamaram, mas não foi tanto para esperar que você desse a resposta. Alguns, que já sabiam resolver, foram procurar alternativas e eu também fiquei bastante surpresa. Eu acho que nosso caminho é esse mesmo, eles vão surpreender e a gente pode receber um resultado satisfatório (depoimento verbal da professora de História).

O processo de reflexão foi fundamental para a análise do projeto e das dificuldades encontradas em sua aplicação. Ao tratar da importância da reflexão na formação permanente do professor, Freire (1996, p. 44) afirma: 
Por isso é que, na formação permanente dos professores, o momento fundamental é o da reflexão crítica sobre a prática. É pensando criticamente a prática de hoje ou de ontem que se pode melhorar a próxima prática. O próprio discurso teórico, necessário à reflexão crítica, tem de ser de tal modo concreto que quase se confunda com a prática.

Além da reflexão realizada diariamente sobre as atividades aplicadas, os professores envolvidos escreviam um diário de bordo no final de cada dia de aplicação do projeto. No último dia, os alunos apresentaram o resultado de seus trabalhos e avaliaram o processo. Foi importante para o grupo o retorno dado pelos alunos, já que, por exemplo, muitos destacaram, como diferencial do projeto, a apresentação dos objetivos traçados na forma de desafios a serem alcançados sob a responsabilidade deles. Nessa etapa, constatamos o envolvimento e o interesse dos alunos, que por sua vez assumiram a responsabilidade de execução do projeto de trabalho, confirmando a hipótese de que a informática pode ser um instrumento motivador da aprendizagem.

A última etapa, de avaliação e reflexão, foi sobre a prática realizada pelo grupo de professores, que se revelou fundamental para a sistematização de todo o trabalho realizado e para a possibilidade de sua continuidade, pois " [...] não existe melhor pedra de toque para a capacidade de pensamento do que $o$ uso que se faz dos próprios enganos e erros [...]" (DEWEY, 1979, p. 119). O que poderia ser um fator de desânimo para o grupo tornou-se, pela reflexão, o ponto de partida para novos rumos de trabalho. Segundo Dewey (1979), enganos e os erros, para o investigador experimentado, podem ser um estímulo e um guia para novos projetos.

\section{Considerações finais}

Atualmente, como em outras épocas, a educação enfrenta os desafios de formação dos indivíduos, principalmente porque a sociedade tem passado por grandes transformações decorrentes dos avanços tecnológicos, especificamente das Tecnologias da Informação e da Comunicação (TICs), que estão influenciando todos os aspectos da sociedade. (ASSMAN, 1998) 
Os programas de formação e capacitação de professores para o uso das TICs e para promover a inclusão digital são ações desenvolvidas na expectativa de formar profissionais da educação aptos a enfrentar essas mudanças. Porém, o que encontramos em nossas escolas públicas é um cenário muito diferente do esperado: nossos professores não se sentem preparados diante de tantas mudanças, desejam prosseguir, mas não sabem por qual caminho, pois, como observamos neste trabalho, não basta equiparmos a escola com laboratórios e softwares na expectativa de sua boa utilização pedagógica. Esse estudo apontou algumas dificuldades que ainda hoje ${ }^{3}$ são recorrentes entre os professores:

- O paradigma educacional no qual muitos professores se baseiam para a utilização da tecnologia na educação é ainda, majoritariamente, o instrucionismo (PAPERT, 1988), ou seja, a instrução mediada pelo computador.

- O processo de implantação das salas-ambiente de informática na escola não contempla um envolvimento real dos professores.

- O preparo técnico deficitário é uma das principais dificuldades e a falta de apoio técnico no laboratório são motivos de insegurança para os professores. Essa insegurança é um dos obstáculos para não levar os alunos ao laboratório. O risco de que o aluno saiba mais sobre computador que o próprio professor coloca em cheque o seu papel em sala de aula.

- Os cursos de capacitação propostos para o uso da informática educativa não priorizaram a reflexão sobre a prática pedagógica nem a contextualização do conhecimento teórico desta prática.

Verificamos que a reflexão sobre a prática pedagógica possibilita a busca pela formação técnica necessária, entretanto, o que observamos nos relatos dos professores, sobre a avaliação dos resultados dos cursos de capacitação propostos antes da pesquisa, é o processo inverso: oferece-se a formação técnica na expectativa de que a reflexão sobre a utilização pedagógica venha como consequência, e isto não aconteceu com o grupo pesquisado.

Assim, o estudo desenvolvido, na forma de uma formação em serviço, evidenciou a importância de se adotar um referencial teórico-epistemológico e metodológico para subsidiar o processo de inserção das tecnologias na prática pedagógica do professor. A Teoria das Situações Didáticas proposta por Brousseau (1986; 1983) contribuiu para desencadear o processo de reflexão e de construção 
do conhecimento pelo grupo investigado, demonstrando ser um modelo teóricometodológico favorável para a formação do professor reflexivo e autônomo. E sinaliza para a importância do trabalho pedagógico coletivo na escola, na perspectiva da formação permanente, continuada e em serviço e, principalmente, da reflexão sobre a prática.

\section{Notas}

10 trabalho completo dessa pesquisa pode ser consultado em Paranhos (2005).

2 Vídeo desenvolvido pela Secretaria da Educação do Estado de São Paulo: A escola de cara nova na era da informática.

3 Resultados semelhantes foram obtidos em uma pesquisa desenvolvida recentemente e que consistiu na análise e reflexão sobre a contribuição da formação continuada para uso do laptop educacional, realizada no contexto de implantação do Projeto "Um computador por aluno" (PROUCA) - projeto piloto-fase II, em uma das escolas públicas municipais de Terenos, MS. (CAMILOTTI e GOBARA, 2012)

\section{Referências}

ALARCÃO, I. Professores reflexivos em uma escola reflexiva. São Paulo: Cortez, 2003.

ALMEIDA, M. E. B. e PRADO, M. E. B. B. Indicadores para a formação de educadores para a integração do laptop na escola. In: ALMEIDA, M. E. B. e PRADO, Maria E. B. B. (Org.). O computador portátil na escola: mudanças e desafios nos processos de ensino e aprendizagem. São Paulo: AVERCAMP. 2011. p. 34 - 48.

ASSMAN, H. Reencantar a educação: rumo à sociedade aprendente. Petrópolis, RJ: Vozes. 1998.

BRANDÃO, H. N. Introdução à análise do discurso. Campinas: UNICAMP, 2002.

BRASIL. MEC. Secretaria de Educação a Distância. Proinfo: informática e formação de professores, v. 2. Brasília, DF: Seed. 2000. p.139.

BROUSSEAU, G. Fondements et méthodes de la didactique des mathématiques. Recherches en didactique des mathématiques. Grenoble, France: La Pensée Sauvage, v. 7, n. 2, 1986. . Les obstacles épistémologiques et les problèmes en mathématiques. Recherches en didactique des mathématique, Grenoble, France: La Pensée Sauvage, v. 4, n. 2. 1983. 
CAMILOTTI, D.C., GOBARA. S.T., Formação continuada para integração do laptop educacional: contribuições para a mudança na prática pedagógica do professor. In $I$ Seminário Internacional de Educação a Distância. 28-30 de novembro, Natal/RN 2011.

DEWEY, J. Como pensamos: como se relaciona o pensamento reflexivo com o processo educativo. São Paulo: Nacional, 1979.

FREIRE, P. Pedagogia da autonomia. Saberes necessários à prática educativa. São Paulo: Paz e Terra, 1996.

FREITAS, J. L. M. Situações didáticas. In: Educação matemática. Uma introdução. p. 65-87. São Paulo: EDUC, 2002.

HENRY, M. Didactique des Mathématiques. Une présentation de la didactique em vue de la formatiosn de enseignants. France: IREM, 1992 p.7

FULLAN, M.; HARGREAVES A. A escola como organização aprendente: buscando uma educação de qualidade. Porto Alegre, RS: Artes Médicas, 2000.

KENSKI, V. M. Educação e tecnologias: o novo ritmo da informação. Campinas, SP: Papirus, 2007.

MORAN, J. M. Informática na educação: Teoria \& Prática, Porto Alegre, v. 3, n. 1, set. 2000.

PAPERT, S. LOGO: computadores e educação. São Paulo: Brasiliense, 1988.

PARANHOS, L. R. L. Da possibilidade para o real: uma pesquisa-ação sobre a formação de professores reflexivos e autônomos na utilização da Informática na Educação. 2005. 199f. Dissertação (Mestrado em Educação) - Universidade Federal de Mato Grosso do Sul, Programa de pós-Graduação em Educação, Campo Grande, 2005.

PARANHOS, L. R. L.; GOBARA, S. T. Limites e possibilidades da ação docente frente as mudanças: a voz dos professores. In: Encontro Regional do ICET Internacional Council on Education for Teaching, 1, 2005, São Carlos. Atas do Encontro Regional do ICET Internacional Council on Education for Teaching. São Carlos: Prograd, 2005.

Reflexão da prática pedagógica: uma pesquisa-ação sobre formação de professores. In: X Congresso Estadual Paulista sobre Formação de Educadores, 1, 2009, Águas de Lindóia, Atas X Congresso Estadual Paulista sobre Formação de Educadores, São Paulo: UNESP, 2009.

THIOLLENT. M. Metodologia da pesquisa-ação. São Paulo: Cortez, 1998.

recebido em 10 set. 2012 / aprovado em 16 nov. 2012

Para referenciar este texto:

GOBARA, S. T. Formação continuada para o uso das Tecnologias de Informação e Comunicação. Dialogia, São Paulo, n. 16, p. 65-79, 2012. 
